Relations industrielles

Industrial Relations

\title{
Le règlement des conflits de droit
}

Volume 9, numéro 3, juin 1954

URI : https://id.erudit.org/iderudit/1022876ar

DOI : https://doi.org/10.7202/1022876ar

Aller au sommaire du numéro

Éditeur(s)

Département des relations industrielles de l’Université Laval

\section{ISSN}

0034-379X (imprimé)

1703-8138 (numérique)

Découvrir la revue

Citer ce document

(1954). Le règlement des conflits de droit. Relations industrielles / Industrial Relations, 9(3), 298-298. https://doi.org/10.7202/1022876ar

Tous droits réservés (C Département des relations industrielles de l’Université Laval, 1954
Ce document est protégé par la loi sur le droit d'auteur. L’utilisation des services d'Érudit (y compris la reproduction) est assujettie à sa politique d'utilisation que vous pouvez consulter en ligne.

https://apropos.erudit.org/fr/usagers/politique-dutilisation/ 


\section{Hausse inévitable des Salaires}

Sans doute, le mouvement de hausse des salaires dont les caractéristiques viennent d'être décrites, pourra être retardé de ci de là, sous l'influence de circonstances économiques ou sociales passagères; mais, pour les mêmes raisons, il pourra s'accélérer à d'autres moments. En fin de compte, il est inévitable.

Une circonstance inévitable comme ce mouvement de hausse des salaires n'étant que passagèrement différable, doit être considérée, comme un fait, comme une donnée du problème qui se pose aux dirigeants, comme un point dont il faut partir si l'on veut aboutir. C'est là, à mon sens, qu'un mouvement patronal peut intervenir et se rendre grandement utile dans une oeuvre absolument essentielle: celle de la formation sociale et personnelle des dirigeants financiers et industriels, formation sans laquelle il n'est pas possible d'entrevoir la solution des problèmes qui se posent à vous aujourd'hui, pris que vous êtes dans une transformation industrielle en grande partie venue du dehors et réalisée par les méthodes du dehors.

Dans cette oeuvre de formation personnelle et sociale du dirigeant, le mouvement se devrait d'être un unitiateur, un promoteur, quitte à abandonner telle ou telle partie de cette formation aux institutions les plus propres à réaliser l'éducation souhaitée. Entendue de la sorte, laction du mouvement serait une action de recherches, d'opinion autant ou plus qu'une action d'exécution.

\section{LE REGLEMENT DES CONFLITS DE DROIT}

Les 3 et 4 mai dernier, se réunissaient au 9è Congrès des Relations Industrielles organisé par le Département des Relations Industrielles de l'Université Laval un nombre imposant de représentants de tous les milieux du travail. Tous, directement ou indirectement intéressés par les problèmes industriels, ont contribué, soit au cours des conférences, soit au cours des délibérations, à rendre intéressant ce congrès dont le thème était: «Le règlement des conflits de droit». Les chiffres suivants illustrent exactement la répartition des congressistes:

\section{Distribution des délégués}

Entreprises et associations patronales...

$\begin{array}{llllllllllll}\text { Syndicats ouvriers } \ldots . . & \ldots & \ldots & \ldots & \ldots & \ldots & \ldots & \ldots & \ldots & \ldots & \ldots & \ldots .\end{array} \quad 170$

Gouvernements fédéral et provincial, municipalités ... .... 84

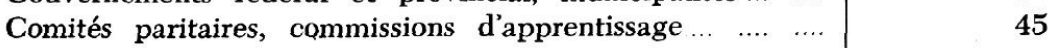

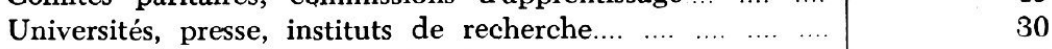

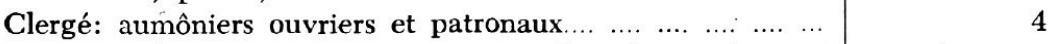

